\title{
A new approach of CMT seam welding deformation forecasting based on GA-BPNN
}

\author{
Yao Lu, Yanfeng Xing*, Xuexing Li, Sha Xu \\ School of Mechanical and Automotive Engineering, Shanghai University of Engineering Science, China \\ edison.lu@foxmail.com,smsmsues@163.com,megres.li@foxmail.com,xytongxing376@sina.com
}

\begin{abstract}
Welding deformation affects the quality of the welded parts. In this paper, by introducing improved back propagation neural network (BPNN), a cold metal transfer (CMT) welding deformation prediction model for aluminum-steel hybrid sheets is established. Before applying BPNN, important parameters affecting welding deformation were obtained by orthogonal test and gray relational grade theory. The accuracy of welding deformation prediction of BPNN is improved by genetic algorithm. The results show that compared with the prediction method based on traditional theory, the deformation prediction model based on GA-BPNN has higher accuracy. Predicted results were applied to the aluminum-steel CMT seam welding in the form of inverse deformation, and the deformation of the welded plate was significantly improved.
\end{abstract}

KEYWORDS. Cold metal transfer welding; Orthogonal test; Gray relational grade theory; BP neural network; Genetic algorithm.

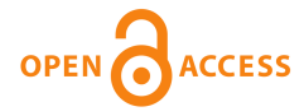

Citation: Yao, Lu., Yanfeng, Xing., Xuexing, Li., Sha, Xu., A new approach of CMT seam welding deformation forecasting based on GA-BPNN, Frattura ed Integrità Strutturale, 53 (2020) 325-336.

Received: 11.01 .2020

Accepted: 18.05 .2020

Published: 01.07.2020

Copyright: (C) 2020 This is an open access article under the terms of the CC-BY 4.0 , which permits unrestricted use, distribution, and reproduction in any medium, provided the original author and source are credited.

\section{INTRODUCTION}

A luminum alloy has the advantages of light weight, strong corrosion resistance and good durability. Therefore, the replacement of the traditional steel structure by the aluminum-steel hybrid structure is an effective means to realize the lightweight of the automobile. Aluminum-steel hybrid sheet with traditional joining method has poor mechanical properties, so in recent years, new metal sheet joining technologies such as cold metal transfer welding [1], self-piercing riveting [2], and friction stir welding [3] have received increasing attention and application. CMT technology has the advantages of low heat input and no spatter transition. The basic principle of the CMT process is a short circuit transition. Each time the short circuit occurs, the welding wire is mechanically retracted, which assists the droplet to detach at relatively low welding currents, and thus the welding heat input can be significantly reduced. Therefore, the CMT process is suitable for the welding of thin gage aluminum alloys with corresponding low distortion and high quality. There is no splash in the welding process, and the weld seam is beautifully formed [4].

Due to the large difference in material properties such as linear expansion coefficient and thermal conductivity of aluminum and steel, welding deformation occurs in the aluminum alloy CMT welding process, which affects the 
manufacturing process of the welded structure. At present, the main methods for researchers to predict welding deformation are three-dimensional thermoelastic finite element method and inherent strain method. Deng et al. [5] predicted the residual stress distribution in low alloy steel and stainless steel dissimilar metal round pipe joints based on the thermoelastic model. Xia [6] used the three-dimensional thermoelastic finite element method to predict the residual stress and deformation of steel plates with different thicknesses. Liang [7] used the three-dimensional thermoelastic finite element method and the inherent strain method to predict the welding deformation of $1 \mathrm{~mm}$ ultra-thin plate. The threedimensional thermoelastic-plastic finite element method tracks the entire thermal cycle of the welding process, and can obtain the temperature field and stress field of the welded plate at any time during the welding process and the cooling process. However, due to the current computer level limitation, the three-dimensional thermoelastic finite element method cannot be applied to complex practical engineering. The inherent strain method can economically predict large and complex structural deformations with short calculation times, but the precision is low [8]. Therefore, it is particularly important to find a method that is highly accurate and can be applied to practical complex engineering problems to predict the deformation of the welded plate.

In the actual welding process, the factors affecting the welding deformation are complex and nonlinear [9]. While BPNN has significant advantages in possessing associative inference and adaptive capacity, and particularly it can be applied to processing various kinds of nonlinear problems [10]. BP neural network is a multi-layer feed forward neural network. Its essence is to approximate the input-output relationship of complex structures by multiple fittings with simple nonlinear functions [11]. BP neural network has been applied to the prediction of connection technology performance such as pulse MIG welding [12], imprint connection [13], resistance spot welding [14], Although BPNN has good local optimization ability, it cannot find the optimal solution in the global scope. BPNN is easy to fall into local extreme points, restricting the accuracy of the neural network [15]. Genetic algorithm (GA) is an efficient global optimization search algorithm. The search spans the entire solution space and has strong global optimization ability. The combination of GA and BP algorithm can be used to find the best connection right in the global scope, to avoid the network falling into local minimum points, and get the optimal solution [16]. Therefore, the combination of GA and BPNN can improve the prediction accuracy of welding deformation of aluminum-steel sheet. Moreover, the deformation predicted by the GABPNN method can be controlled by the inverse deformation method.

In this paper, CMT welding orthogonal test was carried out on AA6061-T6 aluminum alloy and DP590 steel sheet by CMT welding technology. The gray relational grade theory is used to analyze the influence of CMT welding parameters on the welding deformation of aluminum steel. Then, based on BP neural network and GA-BP neural network, the welding deformation is predicted. The predicted results are applied to the welding by the inverse deformation method, which effectively controls the deformation of the welded plate.

\section{METHODOLOGY}

\section{Welding parameter selection method}

he main parameters of CMT welding include wire feed speed, welding speed, arc correction, Aluminum plate thickness, etc. Different parameters have different effects on welding deformation. In order to facilitate the research, this paper screens out the main parameters for the large deformation of the welding based on the orthogonal test and grey relational grade theory.

The basic idea of the grey relational grade theory is to judge the degree of correlation between the factors according to the degree of similarity between the curves, which can be used to determine the contribution of factors to a certain behavior or indicator by quantitatively analyzing the dynamic development process of the system $[17,18]$. This method can be used to analyze the extent to which various factors affect the results and can be used for nonlinear data relationships. The reason why this method is used is to screen out the process parameters that have a great influence on CMT welding deformation, thus simplifying the late neural network prediction model. Because the welding parameters and the welding deformation amount show a highly nonlinear relationship, the gray correlation analysis theory is used to investigate the influence of CMT welding parameters on the welding deformation. The analysis steps are as follows.

Let the reference sequence be:

$$
Y=\{y(k) \mid k=1,2, \cdots, n\}
$$

The comparison sequence is: 


$$
X_{i}=\left\{X_{i}(k) \mid k=1,2, \cdots, n\right\}, i=1,2, \cdots, m
$$

The four factors selected in this article have different physical meanings, so the data dimensions are different. In order to facilitate the comparison between the factors, the data is first normalized. The normalization formula is as follows:

$$
x_{i}(k)=\frac{X_{i}-\min (X)}{\max (X)-\min (X)}, i=1,2, \cdots, n
$$

Calculate the correlation coefficient $\xi_{i}(k)$ between $y(k)$ and $x_{i}(k)$ at time $k$, which yields:

$$
\xi_{i}(k)=\frac{\min _{i} \min _{k}\left|y(k)-x_{i}(k)\right|+\rho \max _{i} \max _{k}\left|y(k)-x_{i}(k)\right|}{\left|y(k)-x_{i}(k)\right|+\rho \max _{i} \max _{k}\left|y(k)-x_{i}(k)\right|}
$$

In the formula: $k$ is the time; $\rho$ is the resolution; the value range is $(0,1)[19]$; this article takes 0.8 ; $\min _{i} \min _{k}\left|y(k)-x_{i}(k)\right|$ and $\max _{i} \max _{k}\left|y(k)-x_{i}(k)\right|$ are the minimum and maximum differences of the two levels, respectively.

Since the correlation coefficient is the correlation degree between the comparison sequence and the reference sequence at each time, the value is too scattered to be detrimental to the overall comparison. Therefore, the average value of the comparison between the two columns $r_{i}$ is as follows:

$$
r_{i}=\frac{1}{n} \sum_{k=1}^{n} \xi_{i}(k), k=1,2, \cdots, n
$$

The magnitude of the correlation characterizes the relative influence of the comparison sequence on the reference sequence.

\section{Establishment of GA-BPNN model}

The steps of predicting aluminum-steel CMT welding deformation by GA-BPNN are as follows:

1) Determine the structure of BPNN. This paper uses a parallel network structure, including the input layer, hidden layer and output layer. The number of input and output layers is determined by test parameters and evaluation indicators. The transfer function used in this paper is:

$$
f(x)=\frac{1}{1+e^{-x}}
$$

This function maps the real field to the $[0,1]$ space smoothly. In addition, the function is monotonically increasing, continuous and derivable, and the derivative form is very simple, which is a suitable function.

2) Initialize the weight coefficients connecting the input layer, hidden layer and output layer of the BPNN;

3) Code the chromosomes of the weight coefficients and set the GA parameters. In this paper, the individual coding length of the genetic algorithm is 21 . The parameters of the genetic algorithm are set as follows: the population size is 10 , the number of evolutions is 50 , the crossover probability is 0.4 , and the mutation probability is 0.2 .

4) Design the fitness function and calculate the corresponding fitness value of current chromosomes. The fitness function is designed as:

$$
F=\sum_{i=1}^{n} a b s\left(y_{i}-o_{i}\right)
$$

( $n$ denotes the number of neurons in the output layer, $o_{i}$ and $y_{i}$ represent the predicted and actual outputs of the ith neuron, respectively) 
5) Do the selection crossover and mutation to produce the best fitness values;

It went on the step 5's process of iterative evolution until getting the Near-Optimal fitness value or going to the default maximum generation of evolution. The output of this process was the individual with the best fitness, and the individual consists of the weights and threshold, which would be used as the final weights and thresholds of the BPNN.

Fig. 1 illustrates the solution procedure of the GA optimized BPNN method for deformation forecasting of aluminumsteel CMT welding.

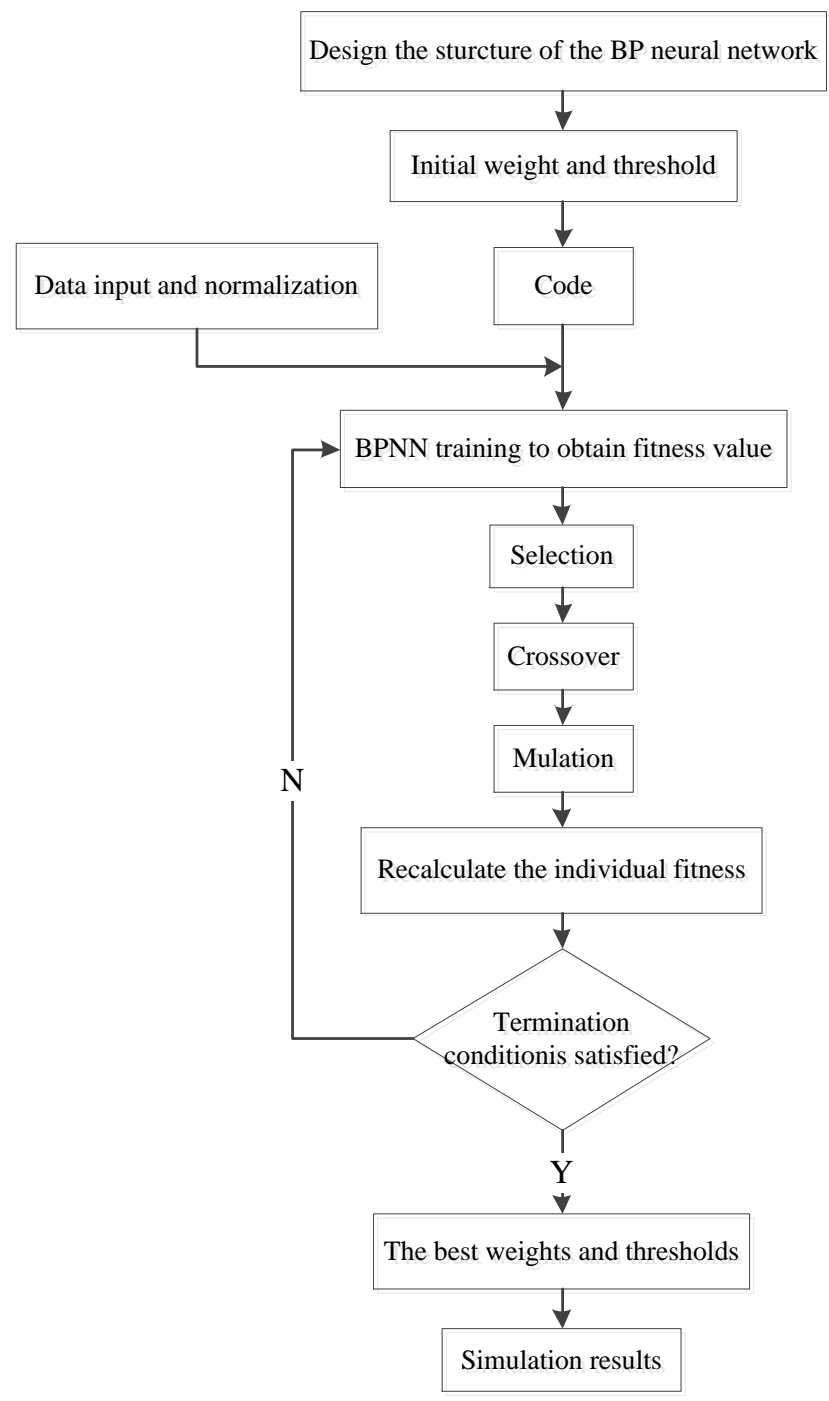

Figure 1: The flow chart of GA Optimized BPNN method

After the GA-BPNN model is established, it can be used to deal with complex nonlinear problems, which provides a reference for the subsequent prediction of aluminum steel welding deformation.

\section{The inverse deformation method}

The inverse deformation method [20] pre-estimates the direction and size of the structural deformation, and gives the sheet a deformation in the opposite direction during assembly, which is used to offset the deformation caused by the welding, so that the post-weld member maintains the design requirements. After extensive experimental observation, the aluminum-steel sheet CMT welding will undergo warping deformation. The warping deformation shape of the aluminum sheet side is low in the middle and high on both sides. Therefore, the same deformation in the opposite direction is applied to the sheet before welding, so that the sheet is restored to a flat shape after welding. In this paper, the estimated size of deformation is given by GA-BPNN. The anti-deformation treatment diagram is shown in Fig. 2. 


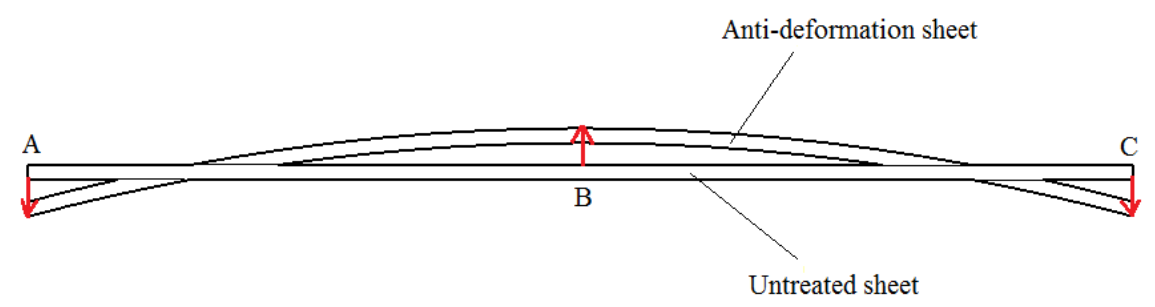

Figure 2: Anti-deformation treatment diagram

\section{RESULTS AND DISCUSSION}

A A6061-T6 aluminum alloy and DP590 steel commonly used in the automotive industry are used as test plates. So in this paper, AA6061-T6 aluminum alloy and DP590 steel are used as test plates, and ER4043 (AlSi5) with a diameter of $1.2 \mathrm{~mm}$ is used as a filler wire. An aluminum plate having a thickness of $1 \mathrm{~mm}, 1.2 \mathrm{~mm}, 1.5 \mathrm{~mm}$, and $2 \mathrm{~mm}$ and a steel plate having a thickness of $1.2 \mathrm{~mm}$ are cut into a sample having a length $\times$ width of $150 \mathrm{~mm} \times 50 \mathrm{~mm}$ by a wire cutter. Before the test, the aluminum plate is polished with sandpaper to remove the oxide film, and then the surface of the steel plate is cleaned with an acetone solution to remove stains, grease, and the like on the surface. The test adopts the lap joint method, the upper layer is aluminum plate and the lower layer is steel plate., and the lap joint amount is $150 \mathrm{~mm} \times 10 \mathrm{~mm}$. Fig. 3 is a schematic view of CMT seam welding of aluminum-steel sheet.

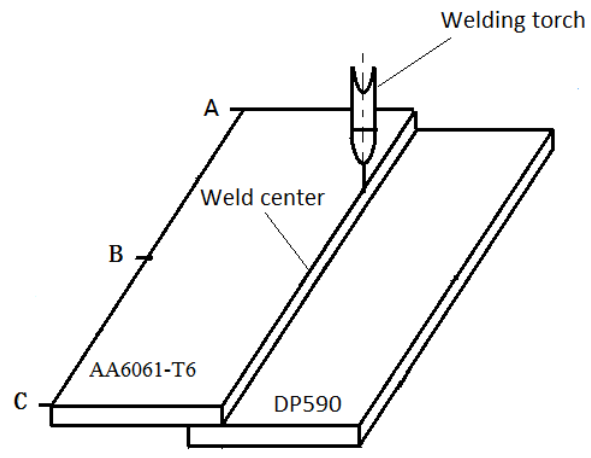

Figure 3: Illustration of seam welding of AA6061-T6/DP590 sheet

The welding equipment required for this test includes the TPS4000 CMT welder from Fronius, welding torch and KUKA robot arm. The welding torch and the surface of the welded part are at an angle of $45^{\circ}$, and the aluminum-steel sheet is welded in a single pass. High purity argon was selected as the shielding gas in the test and operated at a flow rate of 15 $\mathrm{L} / \mathrm{min}$.

During the aluminum-steel CMT seam welding test, the length and width of the aluminum plate and the steel plate were kept unchanged, and 16 groups of tests were carried out according to the five-factor and four-level orthogonal table. The wire feed speed, welding speed, arc correction and aluminum plate thickness were selected as four factors of orthogonal test. The deformation of aluminum-steel sheet was used as the evaluation index of CMT seam welding quality of aluminum-steel. The welding test factor level table is shown in Tab. 1. It was observed that the aluminum plate side showed warping deformation at the middle and low sides after welding. Select the middle point B of point A and point C on the side of the aluminum plate as the measurement point, and then the welding deformation is the height difference between point $\mathrm{B}$ before welding and point $\mathrm{B}$ after welding. The measuring point is shown in Fig. 3. The coordinates of point $\mathrm{B}$ before and after welding is measured by a binocular stereoscopic measuring point device as shown in Fig. 4, and the height difference was calculated manually as the amount of welding deformation.

\section{Welding parameters analysis}

The orthogonal test results of aluminum-steel CMT welding are shown in Tab. 2. In this paper, the deformation of 16 specimens in Tab. 2 was taken as the reference sequence. The corresponding horizontal value-wire feed speed, welding speed, arc correction, and aluminum plate thickness were used as comparison sequence. The data were substituted into the above formula to calculate the correlation degree of each CMT welding parameter to the welding deformation 
amount. The calculation results are shown in Tab. 3. It can be seen from the table that the wire feed speed has the greatest influence on the CMT welding deformation, the welding speed is second, and the arc correction has the least influence.

\begin{tabular}{cccccc}
\hline Level & Factor & A & B & C & D \\
\cline { 3 - 5 } & $\begin{array}{c}\text { Wire feed speed } \\
(\mathrm{m} / \mathrm{min})\end{array}$ & $\begin{array}{c}\text { Welding speed } \\
(\mathrm{mm} / \mathrm{s})\end{array}$ & Arc correction $(\%)$ & $\begin{array}{c}\text { Aluminum plate } \\
\text { thickness }(\mathrm{mm})\end{array}$ \\
2 & 3.6 & 0.56 & -5 & 1.0 \\
3 & 3.9 & 0.62 & 0 & 1.2 \\
4 & 4.2 & 0.66 & 5 & 1.5 \\
& 4.5 & 0.70 & 10 & 2.0 \\
\hline
\end{tabular}

Table 1: Test level of factor

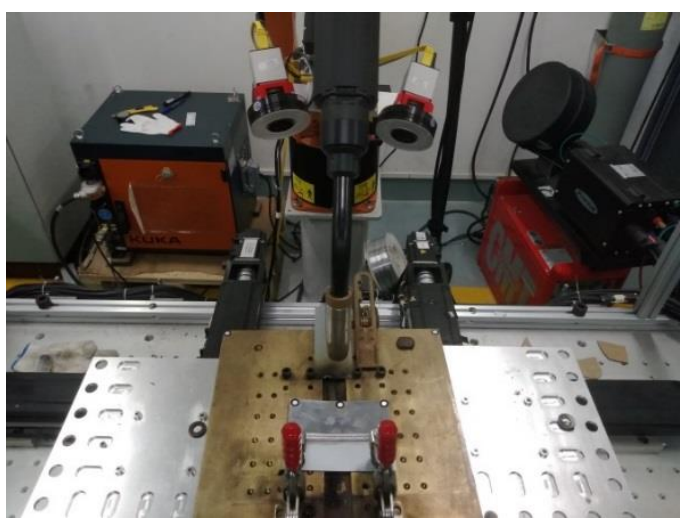

Figure 4: Binocular stereo vision measurement of mark point device

\begin{tabular}{|c|c|c|c|c|c|c|}
\hline \multirow{3}{*}{ Serial number } & \multicolumn{5}{|c|}{ Factor } & \multirow{2}{*}{$\begin{array}{c}\text { Result } \\
\Delta \mathrm{D}\end{array}$} \\
\hline & A & B & $\mathrm{C}$ & $\mathrm{D}$ & $\mathrm{E}$ & \\
\hline & Wire feed speed & Welding speed & Arc correction & $\begin{array}{l}\text { Aluminum plate } \\
\text { thickness }\end{array}$ & Error & Deformation (mm) \\
\hline 1 & 1 & 1 & 1 & 1 & 1 & 0.52 \\
\hline 2 & 1 & 2 & 2 & 2 & 2 & 0.64 \\
\hline 3 & 1 & 3 & 3 & 3 & 3 & 0.48 \\
\hline 4 & 1 & 4 & 4 & 4 & 4 & 0.50 \\
\hline 5 & 2 & 1 & 2 & 3 & 4 & 0.36 \\
\hline 6 & 2 & 2 & 1 & 4 & 3 & 0.40 \\
\hline 7 & 2 & 3 & 4 & 1 & 2 & 0.46 \\
\hline 8 & 2 & 4 & 3 & 2 & 1 & 0.34 \\
\hline 9 & 3 & 1 & 3 & 4 & 2 & 0.50 \\
\hline 10 & 3 & 2 & 4 & 3 & 1 & 0.76 \\
\hline 11 & 3 & 3 & 1 & 2 & 4 & 0.68 \\
\hline 12 & 3 & 4 & 2 & 1 & 3 & 0.58 \\
\hline 13 & 4 & 1 & 4 & 2 & 3 & 0.42 \\
\hline 14 & 4 & 2 & 3 & 1 & 4 & 0.64 \\
\hline 15 & 4 & 3 & 2 & 4 & 1 & 0.52 \\
\hline 16 & 4 & 4 & 1 & 3 & 2 & 0.38 \\
\hline
\end{tabular}

Table 2: Orthogonal test results 


\begin{tabular}{ccccc}
\hline Factor & Wire feed speed & Welding speed & Arc correction & Aluminum plate thickness \\
Correlation degree & 0.727116 & 0.723069 & 0.679584 & 0.721059 \\
\hline
\end{tabular}

Table 3: The correlation degree of each CMT welding parameter to the welding deformation amount

\section{Prediction of welding deformation based on GA-BPNN}

From the gray relational analysis, the wire feed speed, welding speed and aluminum plate thickness are three important parameters that affect the welding deformation. Therefore, BP neural network is used to study the complex nonlinear relationship between three welding parameters (wire feed speed, welding speed, aluminum plate thickness) and one output parameter (welding deformation) to predict the welding deformation of aluminum-steel sheet. The neural network includes 3 input node, 5 implicit layer node, and 1 output layer node. he prediction model of welding deformation of aluminum-steel sheet based GA-BPNN is shown in Fig. 5.

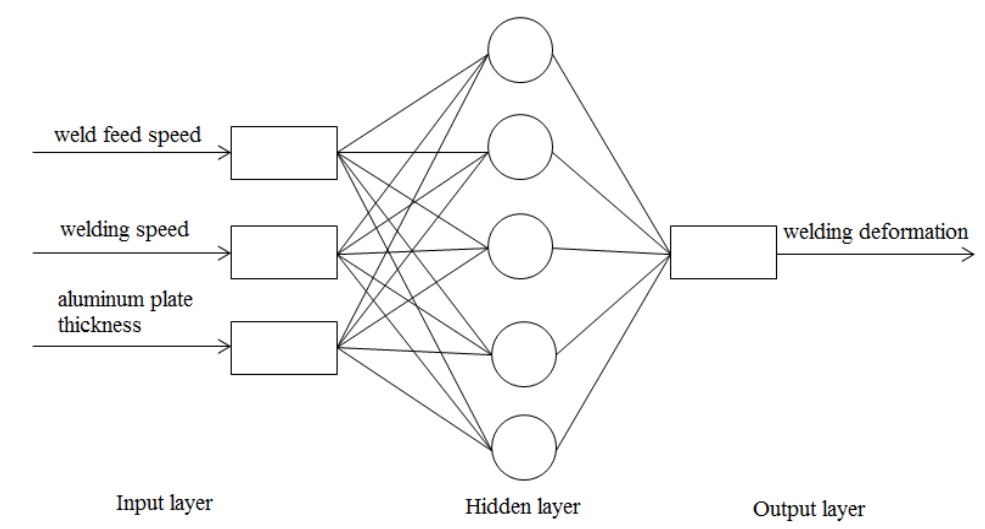

Figure 5: Prediction model of welding deformation based on GA-BPNN

In order to obtain the training samples required for the neural network, 120 sets of CMT seam welding tests were performed on the DP590 steel plate and the AA6061-T6 aluminum alloy plate. Under the condition that the shielding gas flow rate and the preheating temperature are constant, the welding deformation amount under different heat input is obtained by changing the values of the wire feed speed, the welding speed and the aluminum plate thickness process parameters. The measured deformation point is point B in Fig. 3.

After establishing the neural network model, based on the 120 sets of data obtained from the experiment, the first 100 groups were selected for training neural network, and the last 20 groups were used for verification. The operation was performed in Matlab 2016a. The predicted outputs of BPNN and GA-BPNN are shown in Fig. 6 and Fig. 7 respectively. Fig. 8 is the comparison of BPNN and GA-BPNN error.

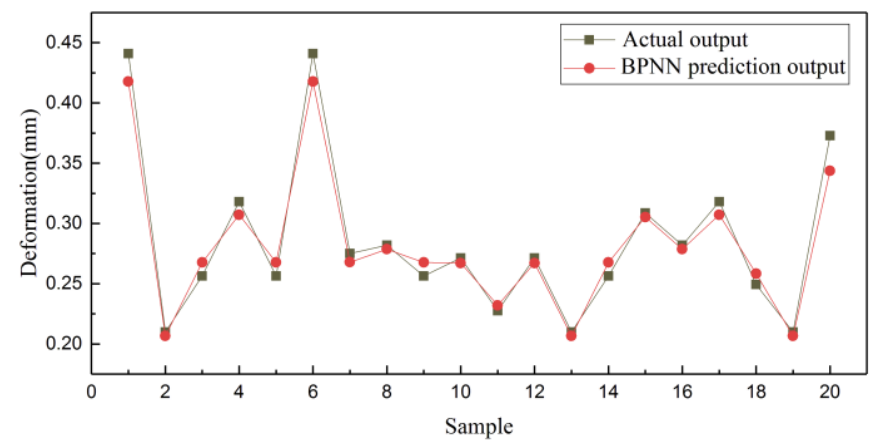

Figure 6: BPNN prediction output

As can be seen from the comparison of Fig. 6 and Fig. 7, the GA-BPNN predicts the amount of welding deformation closer to the actual deformation amount than the BPNN. It can be seen from Fig. 8 that both the BPNN and the GABPNN have fluctuations around the zero point and the GA-BPNN has a smaller fluctuation range. The BPNN prediction 
error range is $-0.029 \mathrm{~mm} \sim 0.011 \mathrm{~mm}$, the maximum relative error is $0.029 \mathrm{~mm}$, and the minimum relative error is $0.003 \mathrm{~mm}$. The GA-BPNN prediction error range is $-0.016 \mathrm{~mm} \sim 0.004 \mathrm{~mm}$, the maximum relative error is $0.016 \mathrm{~mm}$, and the minimum relative error is $2.69 * 10^{-6} \mathrm{~mm}$.

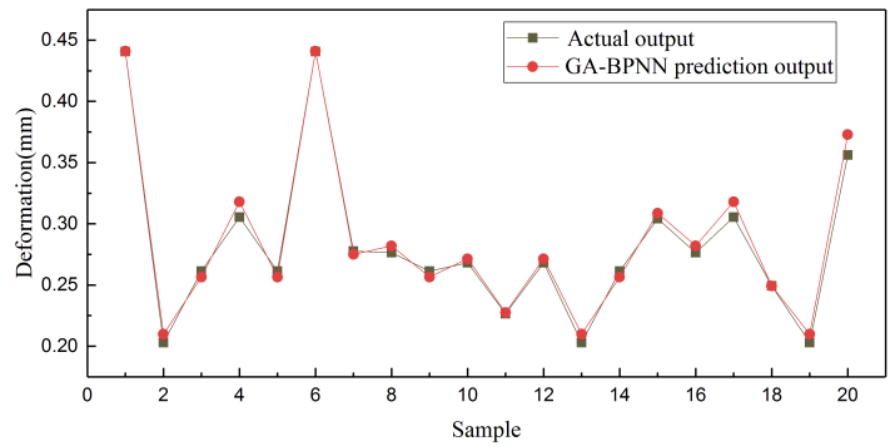

Figure 7: GA-BPNN predictive output

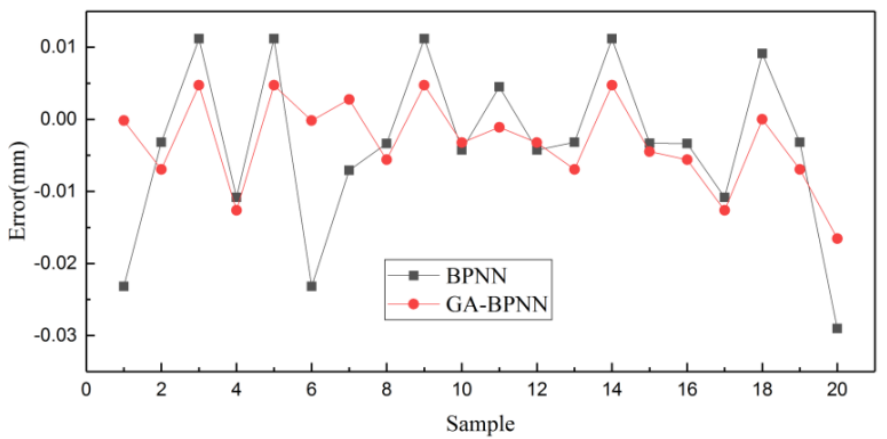

Figure 8: Comparison of neural network errors

The detailed comparison of BPNN and GA-BPNN is given below. Fig. 9 shows the training performance of two neural networks. It can be seen from Fig. 9 that the training error, validation error and test error of the network are decreasing with time, the generalization error is gradually smaller, the generalization ability is improved, and the test curve and the verification curve are consistent. When the circle position in the figure is reached, the generalization error reaches a minimum. The BPNN converges after 4 epochs, and the GA-BPNN converges after 6 epochs. GA-BPNN has a longer convergence time than BPNN because the evolution process of the population takes a long time, and the larger the initial size range of the population size, the number of iterations, the weight and the threshold, the longer the convergence time. Fig. 10 shows the validation results of the trained BPNN. It is noticed from the figure that the gradient index and mutation index of the BPNN is smaller than that of the GA-BPNN. Fig. 11 is the regression analysis of the expected output of the network and the actual training results. It can be seen from Fig. 11 that the correlation coefficient of BPNN is 0.97074 , and the correlation coefficient of GA-BPNN is 0.97843 , indicating that GA-BP network has better regression performance and better generalization capabilities.

Tab. 4 lists the MSE (mean squared error), RMSE (root mean square error) and MAE (mean absolute error) prediction errors. From Tab. 4 we can see that the prediction precision of the GA-BPNN is higher than that with BPNN. For the two patterns, the prediction mean absolute error of BPNN is 0.0095. Contrast with it, the prediction mean absolute error of GA-BPNN is 0.0054. As a result, we can see that the GA-BPNN algorithm has better performance than BPNN. This comparison indicates that taking the advantage of the GA optimization, the BPNN could be trained well with high generalization ability and hence the forecasting performance is superior to the unoptimized neural networks.

$\mathrm{Xu}$ [21] has studied welding deformation based on the traditional method of elastoplastic deformation. In his study, a three-dimensional finite element model for laser welding of a thin plate was established based on the thermal-elasticplastic FEM approach to simulate the temperature field and deformation of the 316L stainless steel in the pulsed laser welding process. A moving volumetric heat source was applied to simulate the laser energy input during the welding process. Meanwhile, the welding deformation was measured by a laser displacement sensor. And the computed results were compared with the measured results. 
Fig. 12 shows the welding deformation results measured by Xu under simulation and test. It can be seen from Fig. 12 that the simulation results have higher accuracy and have good consistency with the test. The MSE 、 RMSE and MAE of Xu's result are calculated. The results are shown in Tab. 4. According to Tab. 4, GA-BPNN has higher prediction accuracy.

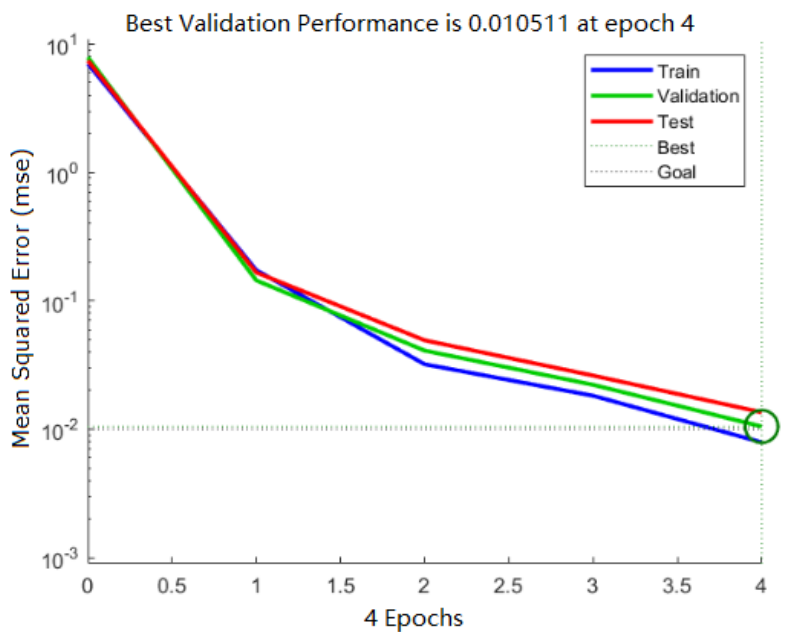

(a)

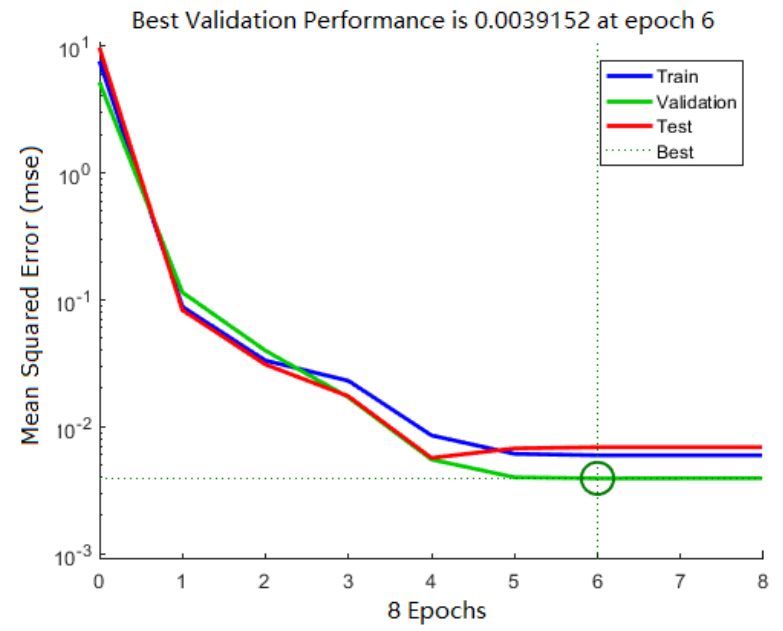

(b)

Figure 9: Comparison of the training performance of two neural networks: (a) BPNN, (b) GA-BPNN.
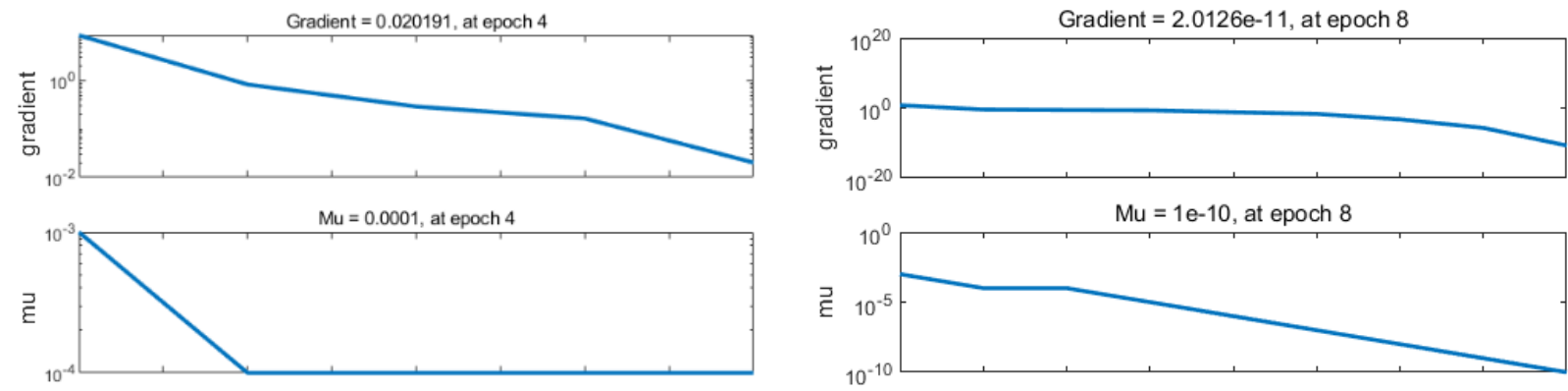

Validation Checks $=0$, at epoch 4
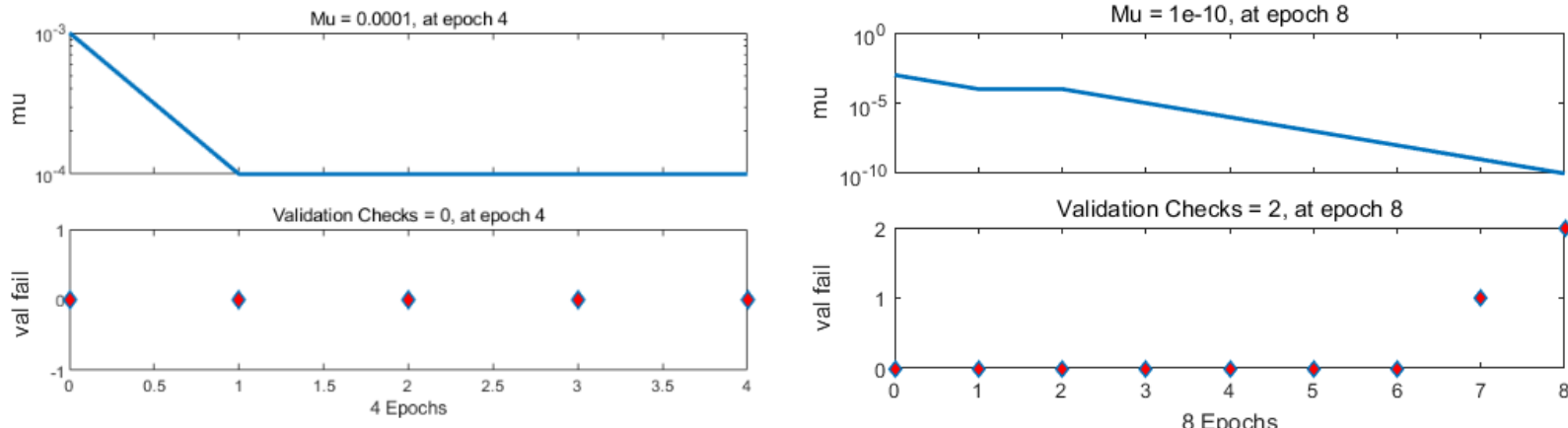

(a)

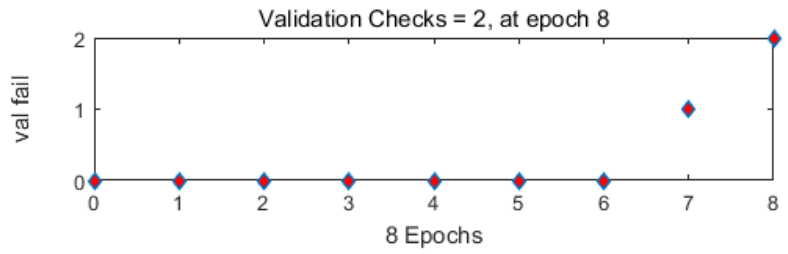

(b)

Figure 10: The training state of two neural networks: (a) BPNN, (b) GA-BPNN.

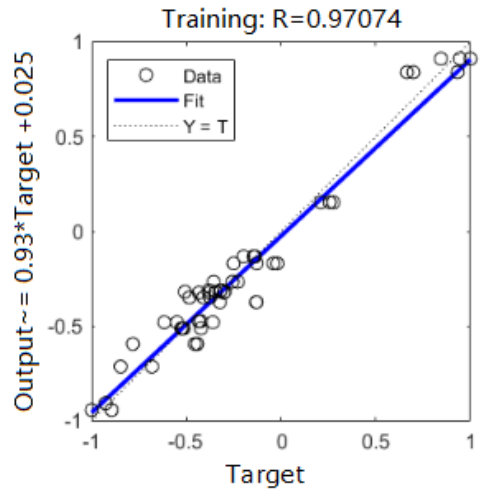

(a)

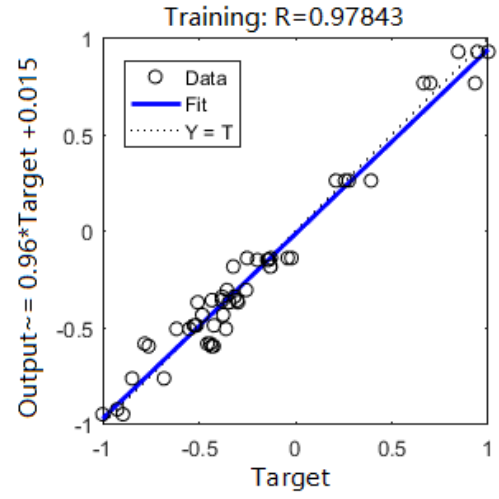

(b)

Figure 11. Regression of two neural networks: (a) BPNN, (b) GA-BPNN. 


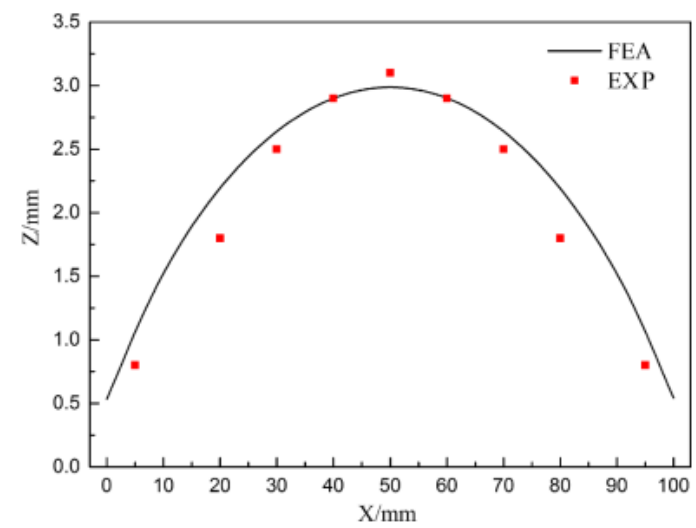

Figure 12: Xu's results of welding deformation under simulation and experiment.

\begin{tabular}{cccc}
\hline & MSE $(\mathrm{mm} 2)$ & RMSE $(\mathrm{mm})$ & MAE $(\mathrm{mm})$ \\
BPNN & 0.00014 & 0.01205 & 0.00953 \\
GA-BPNN & 0.00005 & 0.00686 & 0.00539 \\
Xu's result & 0.233172 & 0.482879 & 0.174549 \\
\hline
\end{tabular}

Table 4: The MSE, RMSE, MAE and MAPE using BPNN and GA-BPNN prediction method.

\section{Welding deformation control and verification}

The welding deformation predicted by BPNN and GA-BPNN was applied to the aluminum-steel sheet by the inverse deformation method to verify the effectiveness of the welding deformation prediction. The aluminum-steel sheets were divided into control experiments, which were no anti-deformation treatment group, BPNN anti-deformation treatment group and GA-BPNN anti-deformation treatment group. In the anti-deformation processing group, the same size deformation was applied to the three points $\mathrm{A}, \mathrm{B}$, and $\mathrm{C}$ of the steel sheet and the aluminum plate before welding which was opposite to the direction of deformation predicted by the neural network. The results of the deformation control experiment are shown in Fig. 13. As can be seen from Fig. 13, the post-weld sheet after the reverse deformation treatment is significantly controlled compared to the post-weld sheet without reverse deformation treatment, and the deformation amount of Fig. 13(c) is smaller than that of Fig. 13(b).

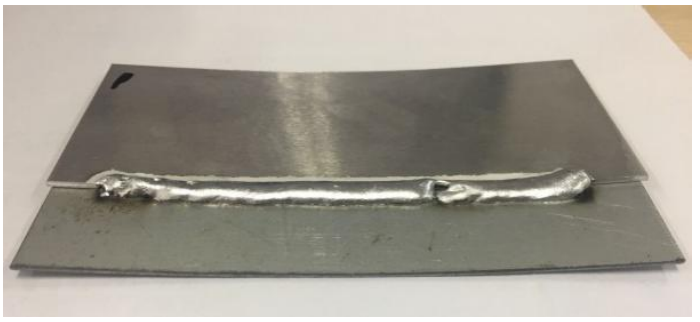

(a) Post-weld plate without reverse deformation treatment

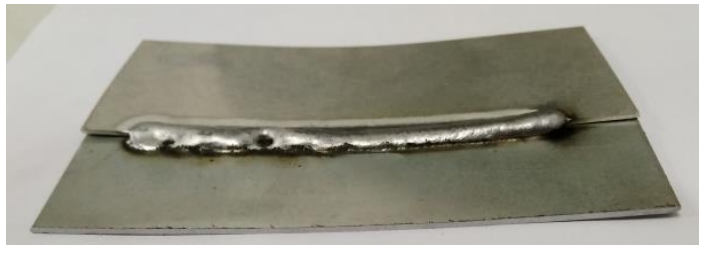

(b) Post-weld plate of BPNN reverse deformation treatment

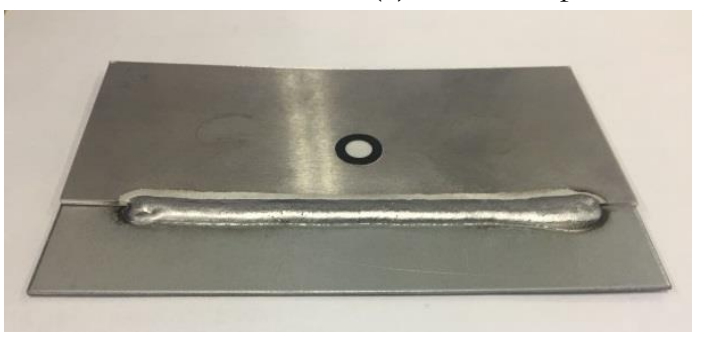

(c) Post-weld plate for GA-BPNN reverse deformation treatment

Figure 13: Contrast test of deformation treatment 
Tab. 5 shows the results of the deformation amount of the control test. It can be seen from the table that in the case where the welding process parameters are the same, the aluminum-steel sheet without anti-deformation warps obviously, and the deformation amount is $0.67 \mathrm{~mm}$. The post-weld deformation of the sheet with the deformation amount predicted by the BP neural network is reduced, and the post-weld deformation is $0.36 \mathrm{~mm}$, and The post-weld deformation of the sheet with the deformation amount predicted by the GA-BP neural network is $0.11 \mathrm{~mm}$ which is much smaller than the sheet with the deformation predicted by the BP neural network. Therefore, the GA-BP neural network can effectively predict the CMT welding deformation of the aluminum-steel sheet compared with the BP neural network, and the error is controlled within a reasonable range.

\begin{tabular}{cccccc}
\hline & $\begin{array}{c}\text { Wire feed speed } \\
(\mathrm{m} / \mathrm{min})\end{array}$ & $\begin{array}{c}\text { Welding speed } \\
(\mathrm{m} / \mathrm{min})\end{array}$ & $\begin{array}{c}\text { Arc correction } \\
(\%)\end{array}$ & $\begin{array}{c}\text { Aluminum plate } \\
\text { thickness }(\mathrm{mm})\end{array}$ & $\begin{array}{c}\text { Deformation } \\
(\mathrm{mm})\end{array}$ \\
$\begin{array}{c}\text { No anti-deformation } \\
\text { BP inverse deformation }\end{array}$ & 3.9 & 0.70 & 0 & 1.5 & 0.67 \\
$\begin{array}{c}\text { processing } \\
\text { GA-BP inverse }\end{array}$ & 3.9 & 0.70 & 0 & 1.5 & 0.36 \\
deformation processing & 3.9 & 0.70 & 0 & 1.5 & 0.11 \\
\hline
\end{tabular}

Table 5: Test result of welding deformation

\section{CONCLUSION}

$\mathrm{I}$ $\mathrm{n}$ this paper, the welding process parameters affecting the CMT seam welding deformation of aluminum-steel are studied by orthogonal test and gray relational grade theory. The influence degree of CMT welding process parameters on welding deformation is analyzed. Then BP neural network and GA-BP neural network were used to predict the welding deformation. The final conclusion is as follows:

(1) Based on the orthogonal test and the gray relational analysis, the wire feed speed has the greatest influence on the aluminum alloy CMT welding deformation, the welding speed is the second, and the arc correction has the least influence.

(2) The BP neural network improved based on genetic algorithm has higher prediction accuracy. The BP neural network prediction error range is $-0.029 \mathrm{~mm} \sim 0.011 \mathrm{~mm}$, the maximum relative error is $0.029 \mathrm{~mm}$, and the minimum relative error is $0.003 \mathrm{~mm}$. However, the GA-BP neural network prediction error range is $-0.016 \mathrm{~mm} \sim 0.004 \mathrm{~mm}$, the maximum relative error is $0.016 \mathrm{~mm}$, and the minimum relative error is $2.69 * 10^{-6} \mathrm{~mm}$.

(3) The prediction results of BP neural network and GA-BP neural network are applied to the welding of the sheet in the form of anti-deformation. The results show that the deformation of the welded plate is obviously smaller. Moreover, the deformation of the post-weld plate with the anti-deformation amount predicted by GA-BP neural network is smallest, indicating that the GA-BP neural network is more suitable for the prediction of CMT welding deformation of aluminum-steel.

In the future, the deformation of aluminum-steel hybrid sheets in more complex assembly forms and under multiple welds will be further studied, and the neural network prediction model proposed in the paper will be used for prediction.

\section{REFERENCES}

[1] Solecka, M., Kopia, A., Radziszewska, A. and Rutkowski, B. (2018). Microstructure, microsegregation and nanohardness of CMT clad layers of Ni-base alloy on 16Mo3 steel, Journal of Alloys \& Compounds, 751, pp. 86-95.

[2] Masters, I., Fan, X., Roy, R. and Williams, D. (2012). Modelling distortion induced in an assembly by the self piercing rivet process, Proceedings of the Institution of Mechanical Engineers. Part B: Engineering Manufacture, 226(2), pp. 300-312.

[3] Rai, R., De, A., Bhadeshia, H. K. D. H. and Debroy, T. (2011). Review: friction stir welding tools, Science \& Technology of Welding \& Joining, 16(4), pp. 325-342.

[4] Lei, H. Y., Li, Y. B. and Carlson, B. E. (2017). Cold metal transfer spot welding of 1, mm thick aa6061-t6, Journal of Manufacturing Processes, 28, pp. 209-219. 
[5] Deng, D., Kiyoshima, S., Ogawa, K., Yanagida, N. and Saito, K. (2011). Predicting welding residual stresses in a dissimilar metal girth welded pipe using $3 \mathrm{~d}$ finite element model with a simplified heat source, Nuclear Engineering and Design, 241(1), pp. 46-54.

[6] Xia, J. and Jin, H. (2016). Numerical study of welding simulation and residual stress on butt welding of dissimilar thickness of austenitic stainless steel, International Journal of Advanced Manufacturing Technology, 91(1-4), pp. 1-9.

[7] Wei, L., Liang, Z. and Xiaolu, S. (2017). Prediction of welding deformation of ultra-thin plates by inherent strain method, Transactions of The China Welding Institution, 38 (3), pp. 103-106.

[8] Jin, Z., Baohua, C., Ye, Z. and Dong, D. (2010). Prediction of welding deformation of aluminum alloy by inherent strain method, Welding Technology, 39(6), pp. 6-10.

[9] Liming, L., Guoli, L., Yujun, L., Zan, Z., Chonghua, Z. and Peisheng, L. (2002). Analysis and Prediction of Welding Deformation of Ship High Strength Steel Based on Artificial Neural Network, Transactions of The China Welding Institution, (01), pp. 27-29+33-3.

[10] Li, Z., Yan, X., Yuan, C., Peng, Z. and Li, L. (2011). Virtual prototype and experimental research on gear multi-fault diagnosis using wavelet-autoregressive model and principal component analysis method, Mechanical Systems and Signal Processing, 25(7), pp. 2589-2607.

[11] Baştanlar Y. and Ozuysal, M. (2012). Introduction to machine learning, An Introduction to Machine Learning. Springer Publishing Company, Incorporated.

[12] Chen, B. and Feng, J. (2014). Modeling of underwater wet welding process based on visual and arc sensor, Industrial Robot: An International Journal, 41(3), pp. 311-317.

[13] Jiangqi, L., Fengchong, L., Jiqing, C. and Ping, A. Y. (2009). Mechanical properties prediction of the mechanical clinching joints based on genetic algorithm and bp neural network, Chinese Journal of Mechanical Engineering, 22(1), pp. 36-41.

[14] Liu, J., Xu, G., Ren, L., Qian, Z. and Ren, L. (2016). Defect intelligent identification in resistance spot welding ultrasonic detection based on wavelet packet and neural network, International Journal of Advanced Manufacturing Technology, 90(9-12), pp. 1-8.

[15] Haisheng, L., Long, L., Li, C., Cheng, L. and Qiang, C. (2015). The prediction in computer color matching of dentistry based on gatbp neural network, Computational and Mathematical Methods in Medicine, pp. 1-7.

[16] Qian, L., Huan, T., Jing, W., Qin, Z., Jie, C. and Zhe, Q. W. (2018). Warfarin maintenance dose prediction for patients undergoing heart valve replacement- a hybrid model with genetic algorithm and back-propagation neural network, Scientific Reports, 8(1), pp. 9712

[17] Niu, H., Yu, J. and Huang, Z. (2017). Gray correlation analysis and chebyshev prediction of air gap discharge voltage, International Conference on Electrical Materials \& Power Equipment. IEEE.

[18]Jian, C., Jingmin, F. and Chenguang, A. (2010). Application of grey correlation analysis in chromatograph peak identification of transformer oil, Power System Technology, 34(7), pp. 206-210.

[19] Yanbin, L., Xinyi, Y. and Zhijie, W. (2013). Risk assessment on photovoltaic power generation project by grey correlation analysis and TOPSIS method, Power System Technology, 37(6), pp. 1514-1519.

[20] Xian, S. (2014). The principle and control of the anti-deformation method of weldment in engineering application, Modern Welding Technology, 12, pp. 38-42.

[21] Hailaing, X., Xingye, G., Yongping, L., Jian, L., Hanguang, F., Rongshi, X. (2019). Welding deformation of ultra-thin 316 stainless steel plate using pulsed laser welding process, Optics And Laser Technology, 119. 